\title{
A AMÉRICA LATINA EM DIÁRIO DE MOTOCICLETA, DE WALTER SALLES E O GÊNERO ROAD MOVIE
}

\author{
Prof. Dr. Gerson Roberto Neumann \\ UFRGS
}

\begin{abstract}
Resumo: Ernesto Che Guevara percorreu a América Latina duas vezes e com isso quis conhecer sua terra e seu povo. Da segunda viagem resultou o livro De moto pela América do Sul. Diário de Viagem, o qual serviu de base para a produção do filme Diário de Motocicleta, do diretor Walter Salles. No presente artigo, pretende-se trazer à discussão a questão do gênero Road Movie, estabelecendo um diálogo entre o texto literário e a produção fílmica. Na discussão em torno dos gêneros será observado como o "estar em movimento" acaba por trans-formar o ser que se encontra em estado de "movimento."
\end{abstract}

Abstract: Ernesto Che Guevara traveled through Latin America twice and he wanted to know his land and his people. The second trip resulted in the book By motorcycle through South America. Travel Journal, which served as the basis for the production of the film The Motorcycle Diary, from director Walter Salles. In this article, we intend to bring to the discussion the issue of the gender Road Movie, establishing a dialogue between literary text and film production. In the discussion of the genres it will be noted how "being in motion" turns out to trans-form the being that is in a state of "motion."

Resümee: Ernesto Che Guevara hat zweimal Lateinamerika bereist und damit wollte er sein Land und dessen Bewohner näher kennen lernen. Aus der zweiten Reise entstand das Buch De moto pela América do Sul. Diário de Viagem [Latinoamericana. Tagebuch einer Motorradreise 1951/52], das als Vorlage für die Produktion des Filmes Diário de Motocicleta, vom Regisseur Walter Salles diente. In diesem Beitrag möchte man den Begriff des Road Movie als Genre in die Diskussion bringen, indem man den literarischen Text und die filmische Produktion diskutiert. Im Gespräch um das Thema soll betrachtet werden wie der Begriff des “In-Bewegung-Sein” den sich “bewegenden” ver-ändert. 


\section{INTRODUÇÃO}

Conhecer o mundo na estrada ou sempre a caminho, já foi há tempos a motivação para muitos deixarem para trás o seu locus amoenus com o objetivo de enfrentar novas realidades e de buscar novas experiências. Exemplos de tais empreitadas há vários, desde as viagens de iniciação ou de formação, tematizadas nas narrativas homéricas, assim como as narrativas de viajantes e desbravadores de regiões até então desconhecidas. São diversas as formas adotadas para percorrer trajetos e depois narrar as aventuras e compartilhar as descobertas realizadas às demais pessoas. São viagens a pé, a cavalo, de navio, atravessando mares e oceanos, de trem, carro, moto, entre outras tantas formas. Essa forma de viajar e conhecer o até então desconhecido pode ser realizada de forma isolada, em dupla ou ainda em pequenos grupos.

Com o presente texto, pretende-se transitar pela obra de um conhecido diretor de cinema brasileiro pela produção de filmes do gênero Road Movie. Trata-se de Walter Salles, conhecido também pelos filmes Terra Estrangeira (este em co-direção com Daniela Thomas) e Central do Brasil. Depois desses dois filmes, Diários de Motocicleta, produção de Salles do gênero, alcançou grande êxito por narrar a trajetória de Ernesto "Che" Guevara antes de sua atividade abertamente revolucionária. Segundo o próprio Walter Salles, como base para o filme tomou-se o livro De moto pela América do Sul. Diário de Viagem, de Ernesto Che Guevara. Aqui se pretende trabalhar especificamente o filme Diários de Motocicleta, sendo que sua outra produção, acima citada, servirá de material complementar que permite uma melhor compreensão da obra do diretor.

Para a presente análise será usado, para tal, também o livro de Ernesto Guevara para que se possa confrontar a transformação que ocorre na personagem Guevara ao longo do filme com a transformação presente no seu próprio relato. Com isso pretende-se, além de observar a transformação da personagem principal nas duas fontes, averiguar até que ponto o diretor se manteve fiel ao diário de viagem de Ernesto Guevara. Visto que uma das características de um filme Road Movie é a transformação interior da pessoa a partir do seu confronto com o exterior, fora do seu meio, com o estranho, esse aspecto será observado de forma mais específica. O confronto da própria realidade com a estranha geralmente resulta em comparações por parte das pessoas que estão na estrada e com isso ocorre a elaboração e interpretação de si mesma.

Também se pretende observar até que ponto e como - com que características do gênero - o diretor realiza um filme Road Movie de fato em Diários de Motocicleta. Diários de Motocicleta pode realmente ser enquadrado nesse gênero? Até que ponto o filme também poderia ser visto como um documentário biográfico sobre a vida do "Che" pré-revolucionário, se é que essa definição de Che Guevara existe?

Por isso, antes da análise do filme propriamente, será apresentada uma progressão sobre o que caracteriza um filme do gênero Road Movie. Para citar um exemplo em relação a essa problemática: Walter Salles afirma ter sido de grande relevância o confronto da personagem principal com a questão social da América Latina. Trata-se de um aspecto que, além de mostrar a transformação de Guevara em figura socialmente envolvida, deve enriquecer e valorizar a produção. Como isso é apresentado no filme do gênero Road Movie? O filme 
dá ao espectador a constatação dessa transformação de cunho social em Ernesto Guevara? Como se percebe isso? São questões relevantes que devem ser tratadas ao longo desse texto sobre o filme Diários de Motocicleta, e que compõem aqui o objeto principal.

\section{O GÊNERO ROAD MOVIE}

Visto que Walter Salles e sua obra em torno da produção de filmes sob a temática Road Movie de cunho documental compõem o centro da atenção nesse momento, crê-se justo e interessante usar, como base para apresentar aspectos da teoria e dos precursores deste gênero, reflexões teóricas do próprio Salles para falar sobre Road Movie, para que se tenha elementos que ratifiquem ou neguem sua aplicação no filme.

Além disso, será usado como material complementar uma interessante produção sobre a temática, lançada em 2006. Trata-se do documentário Wanderlust. On the road with american Movies, uma produção da Tailslate Films, apresentada pela IFC juntamente com a Netflix. São 70 minutos de comentários e opiniões sobre o tema por parte dos principais diretores que se dedicaram a essa produção. Além de Walter Salles, pode-se saber o que pensam sobre o assunto Dennis Hopper, Wim Wenders, Gus van Sant, Barry Levinson, Peter Bogdanovich, Lazlo Kovacs, Robert Benton, Jeanine Basinger, Alexander Payne, entre outros.

O filme Wanderlust é dividido em nove partes: 1. Loking for Adventure; 2. The Road to the Road; 3. The Road to Rebellion; 4. The Road to Nowhere; 5. The 1970's Mood; 6. The Road Splits; 7. American Irony; 8. New Roads/ New Drivers (neste capítulo entra o filme de Walter Salles Diários de Motocicleta) e 9. Monocultural Interstate.

A produção executiva desse filme, que reúne os principais nomes em torno do tema on the road, é de Alison Palmer Bourke e Evan Shapiro, a cinematografia é de Terry Stacey e Nelson Hume, o editor é Tom Donahue e a supervisão de produção da IFC é de Jessica Wolfson. Os diretores do filme são Shari Springer e Berman Robert Pulcini.

O trabalho de registrar por meio da filmagem uma região ou um povo tem seu início na década de 20 do século XX. Até então não se havia realizado o registro de imagens - físicas ou humanas (paisagens e pessoas) - sendo filmadas em movimento. Para Walter Salles, os primeiros documentaristas são Robert Flaherty, com Nanook (1922) e O Homem de Aran (1934) e Basil Wright, com Canção de Ceilão. Antes disso, os registros de lugares e povos ainda desconhecidos já eram realizados por meio de pinturas e pela fotografia e, desta forma, levados para terras distantes.

Para Wim Wenders, por sua vez, a origem dos filmes Road Movie se encontra ainda mais distante na história - na realidade dos povos nômades, na necessidade que o homem sempre teve de deixar um testemunho da sua passagem pela terra. ${ }^{1}$ Assim, todo e qualquer registro deixado por onde o homem tenha passado pode ser tomado como um relato da vida em movimento (pinturas rupestres em cavernas, em rochas, em pedras).

\footnotetext{
${ }^{1}$ Ver também o filme Wanderlust acima citado, pois a produção de Wim Wenders desempenha uma importante função na história do gênero Road Mowie.
} 
Já no cinema, segundo Walter Salles, os primeiros Road Movies representavam a descoberta de um novo território ou a expansão de fronteiras - como os Western norte-americanos. Filmes como Rastros de Ódio (1956), de John Ford, que enfoca o final da guerra civil nos USA e sinalizam para a construção de uma identidade nacional. A seguir, o filme de Edgar Ulmer, Detour (1945), apresenta a sociedade dos USA ainda em transformação, mas já caracterizando indícios de um caminho para um forte individualismo. Depois dos precursores, o filme Easy Rider (1969), de Dennis Hopper, definiu a temática dos Road Movie e se torna referência para o gênero. Neste, o diretor tenta mostrar a perda da inocência do jovem no seu país. Durante esse período ocorrem grandes manifestações de jovens nos USA, os quais defendem uma liberdade total e protestam contra as mortes de muitos compatriotas em combate no Vietnã.

Filmes como esses sugerem que os Road Movies mais interessantes são justamente aqueles em que a crise de identidade do protagonista da história reflete a crise de identidade pessoal, de uma cultura, de um país.

No texto "Entre a ficção e o documentário", que Salles apresenta ao New York Times, existe uma interessante reflexão em torno da relação entre a câmera e as personagens. $\mathrm{O}$ Road Movie é limitado por apenas uma obrigação:

a câmera deve acompanhar as transformações sofridas pelos personagens principais, enquanto estes se confrontam com uma realidade que desconhecem. Por isso, os filmes de estrada não são o território de gruas ou steady-cams, tudo aquilo que é tecnologicamente complexo. Ao contrário, a câmera deve permanecer solidária aos personagens que estão em movimento constante - um movimento que não deve ser controlado. O filme de estrada tende, portanto, a ser caracterizado por um sentido de urgência que não é dissimilar daquele que rege um filme documental. ${ }^{2}$

Para o documentário, sendo um filme do gênero Road Movie ou não, é muito importante a clara distinção entre o que é ficção e o que não é, e para tal é necessário que a câmera acompanhe o contexto e as personagens em questão sem alterações da realidade. No momento em que se inserem elementos alheios aos em questão ou então personagens alheias ao meio para desempenharem papéis de pessoas do meio, pode ser caracterizada a prática ficcional. Neste momento, passa-se a filmar sobre determinado contexto local ou a realidade de determinado povo. Na opinião de Walter Salles, quanto mais a fronteira entre o fato e a ficção estão indefinidos, mais interessante é o resultado. Isso se aplica à participação de personagens que representam a vida das pessoas que realmente são do meio ou também a elementos e dados relevantes no desenvolvimento na filmagem.

Esse dado também vale para o improviso em relação aos eventos da natureza, pois, da mesma forma como se deve saber contornar situações novas presentes não previstas inicialmente na definição e no mapeamento para filmagem, assim também ocorre com a natureza, principalmente em regiões, onde o tempo se caracteriza por sua instabilidade, como, por exemplo, no filme Diários de Motocicleta, na Amazônia. Desta forma, resta se adequar aos eventos da natureza, unir-se a ela. Essa capacidade de improviso é fundamental para filmes do gênero em questão.

2 Ver http://ultimosegundo.ig.com.br/cultura/2007/11/20/entre_a_ficcao_e_o_documentario_1087609.html. 
A situação de fronteira entre um gênero e outro, entre documentário e ficção, pode resultar em trabalhos muito ricos. Citando Godard, Salles afirma que "todos os grandes filmes de ficção derivam na direção do documentário, como todos os grandes documentários derivam na direção da ficção."3

Quanto à estrutura dos filmes Road Movie, pode-se observar uma linearidade na participação das personagens. Existe uma situação inicial, na qual se apresenta o contexto em que está inserida a personagem, sobre quem a história é contada; o que não ocorre, contudo, é a interferência de conflitos externos. Narra-se, sim, a transformação interna dessa personagem, seus conflitos e crises. Citem-se dois exemplos dessa transformação: por um lado David Locke, em Passageiro Profissão Repórter (1975), de Michelangelo Antonioni. Tratase de um jornalista que decide trocar de identidade com um vendedor de armas que sofre um ataque cardíaco no mesmo hotel em que ele está, num vilarejo perdido da África. Por outro lado Philip Winter, em Alice nas Cidades (1974), de Wim Wenders. Winter, também um jornalista, busca uma nova referência em terra estrangeira, uma produção que seja sua. Em ambos os casos, sabe-se que inevitavelmente haverá perdas ao longo do caminho, mas por outro lado também ganhos, reproduzidos em novos conhecimentos e experiências. Essa "troca" de identidade é um exemplo, até certo ponto, radical se se observar a trajetória de Guevara no Diários de Motocicleta, uma vez que neste não ocorre, teoricamente, uma troca identitária, mas uma transformação interior em relação à visão de mundo ao longo da viagem dele com Granado pela América do Sul.

O gênero Road Movie procura registrar a transformação interna das suas personagens; desta forma a maioria dos filmes não é sobre o que pode ser verbalizado, mas sobre aquilo que deve ser sentido - sobre o invisível que complementa o visível. Assim, há muitos momentos de admiração, de silêncio e obeservação, o que para os filmes comerciais muitas vezes pode significar uma perda ou até a perda da atenção do espectador. Para os filmes Road Movie, o momento de silêncio geralmente possui um significado muito mais importante que um momento de ação.

Em relação à importância do improviso nos documentários e filmes Road Movie, cabe ressaltar que não se trata de improvisá-lo completamente. É importante que exista um bom roteiro, pois este permite um melhor improviso. Um bom roteiro permite mais facilmente a inserção de cenas e fatos de improviso. Walter Salles compara esse fato com o jazz: "quanto mais instigante a melodia, mais fácil será bifurcar dela, porque também será mais fácil reencontrá-la mais tarde." ${ }^{4}$

\section{O FILME DIÁRIOS DE MOTOCICLETA}

Antes de Diários de Motocicleta, Salles já viajara pelo Nordeste brasileiro com o seu notório filme Central do Brasil (1998), sexta maior bilheteria do cinema brasileiro com quase dois milhões de ingressos vendidos; e antes ainda com Terra Estrangeira (1995), em par-

\footnotetext{
3 Ver: http://ultimosegundo.ig.com.br/cultura/2007/11/20/entre_a_ficcao_e_o_documentario_1087609.html. 4 Ver http://ultimosegundo.ig.com.br/cultura/2007/11/20/sobre_a_estrutura_e_os_personagens_dos_filmes_de_estrada_1087608.html
} 
ceria com Daniela Thomas, uma viagem de busca entre Brasil e Portugal. Nas suas idas e vindas de produção e experiências, Walter Salles costuma sempre retornar ao gênero que já o caracteriza, o Road Movie de cunho documental.

Em Terra Estrangeira ocorre uma viagem de buscas e trata-se menos de um filme on the road, como o clássico Easy Reader ou então o próprio Diários de Motocicleta. Na verdade, são tentativas de busca por algo que não se tem, por algo melhor, por algo desejado, uma busca de si mesmo ou ainda uma busca por aquilo que é o desejo de outro. A terra estrangeira pode ser o Brasil, deixado para trás, ou pode ser Portugal, onde as figuras centrais da história não estão em casa, por estar o próprio eu fora de seu mundo, cercado por pessoas que não pertencem ao seu meio. Em Terra Estrangeira, Portugal representa a entrada, a possibilidade de conseguir algo melhor, o inverso do que o país representa para os próprios habitantes da terra, que sempre viram no mar a saída para o mundo, o último pedaço de terra firme do continente antes do grande mar. O movimento no filme dá-se na travessia do grande mar e na luta para conseguir retornar ao seu meio, o que em muitos casos leva a voltas desconexas e sem objetividade, ocasionando muitas vezes desfechos frustrados.

Neste filme, Thomas e Salles focam sua atenção mais diretamente na ação das pessoas e nas suas constatntes buscas e com isso é possível acompanhar os dilemas, os sofrimentos, as frustrações a cada momento num mundo estranho. Em meio a encontros e desencontros, o filme termina com uma fuga para algum lugar que não seja o recém-deixado para trás (Portugal), mas existe a busca do passado remoto, do Brasil, que por sua vez não será o mesmo, caso consigam regressar, pois as suas experiências causaram profundas transformações; no caso, em Paco e Alex.

Já em Central do Brasil, a narrativa ocorre em uma região brasileira, o Nordeste, mas que também esconde trechos intransponíveis, da mesma forma como no mar em Terra Estrangeira. Segundo Walter Salles, percorrer o Nordeste brasileiro em Central do Brasil, um rodar pelo interior de seu país, por um pedaço ainda por ser conhecido pelo próprio diretor naquela época, foi uma experiência fascinante. A intenção no filme não foi de rodar esta região brasileira e realizar registros fotográficos em cena, mas de caracterizar a vida das pessoas, a passagem de indivíduos que completam este espaço de chão do Brasil no tempo na sua forma mais natural. Característico no filme é o fato de muitas pessoas não conseguirem se comunicar na forma escrita com seus conhecidos mais distantes, também esta uma forma de viagem, por assim dizer de Road Movie epistolar, uma vez que são palavras que viajam e transmitem as mensagens aos que estão distantes. Assim, cabe à atriz principal, Dora (Fernanda Montenegro), a função de permitir a essas pessoas viajem em forma de cartas com os parentes e amigos distantes. As pessoas a procuram e pedem que ela leia as cartas para elas e também elabore as respostas. Essa tarefa, por sua vez, transforma a personagem que passa a reconhecer nesse meio e nessas pessoas um outro mundo, diferente daquele que lhe era conhecido; tem-se aí um mundo sofrido, pedindo por auxílio e carinho, mas um contexto que possui uma realidade diferente da dela e este contato será fundamental para Dora também aumentar a sua visão de mundo.

Depois dos dois filmes acima, que tematizam o Road Movie, cada qual com suas próprias características, Walter Salles procurou rodar a América do Sul para realizar uma colagem da diversidade de compõe a unidade latino-americana. Por ser baseado no livro que 
resultou do diário de Ernesto Guevara, o filme restringiu-se aos países nele descritos.

Diários de Motocicleta é uma produção da FilmFour, da South Fork Pictures em associação com a Tu Vas Voir Productions. É dirigido por Walter Salles, com roteiro de José Rivera. No elenco figuram Gael García Bernal, Rodrigo de la Serna e Mía Maestro. Os produtores são Michael Nozik, Edgard Tenembaum e Karen Tenkhoff, sendo os produtores executivos Robert Redford, Paul Webster e Rebecca Yeldham. Daniel Burman e Diego Dubcovsky são os co-produtores. A direção de fotografia é de Eric Gautier, A.F.C., a direção de arte é de Carlos Conti e a montagem de Daniel Rezende. Os figurinos foram desenhados por Beatriz di Benedetto e Marisa Urruti e a música é de Gustavo Santaolalla. Gianni Minà é o supervisor artístico.

O filme narra a trajetória de dois jovens argentinos que decidem se aventurar numa viagem de descobrimento pela complexa geografia da América Latina, marcada por sua diversidade, buscando respostas na imagem física e humana do elemento que forma o belo e ao mesmo tempo tão desconhecido continente a que pertencem. Eles procuram desvendar um continente conhecido apenas pelos livros, e ainda assim de forma precária. A aventura inicia no ano de 1952.

O meio de transporte usado por estes cavaleiros andantes ${ }^{5}$ da América Latina é uma motocicleta Norton 500, ano 1939, conhecida como „La Poderosa“ e objeto de louvor principalmente de Alberto Granado, o piloto de 29 anos, um bioquímico que se auto-define como „cientista vagabundo“. O objetivo de Alberto Granado é realizar esta viagem ainda antes dos 30 anos - um sonho antigo. No início do filme Diários de Motocicleta, Alberto tem 29 anos e mora em Córdoba, na Argentina. Trabalha em um hospital local e está incomodado com a forma com que os pacientes lá são tratados. Seu contato com Ernesto Guevara dá-se através do seu irmão mais novo, Tomas Granado. Interessante é o fato de que a personagem de Alberto Granado é interpretada por um primo em segundo grau de Guevera, o jovem ator argentino Rodrigo de la Serna.

O co-piloto, por sua vez, é Ernesto Guevara de la Serna (interpretado pelo mexicano Gael García Bernal), 23 anos, „El Fuser“, estudante de medicina especialista em leprologia, faltando alguns semestres para se formar. Ele vem de uma família de classe média-alta, mas sua curiosidade e interesse vão além dos limites da classe a que pertence. Já no princípio do filme é possível perceber a mudança na percepção de mundo de Ernesto Guevara no que concerne ao pertencimento a uma classe social. Ele é bem informado e já viajara pela Argentina em uma bicicleta, na qual instalara um pequeno motor. A asma é uma preocupação constante desde pequeno, mas ele aprendeu a combatê-la. No filme, a sua asma também é mencionada, tanto no princípio do filme, quando a mãe o lembra das medicações para a doença, assim como em uma viagem de barco, quando Ernesto tem um acesso agudo de asma.

O plano de viagem dos jovens aventureiros argentinos é percorrer oito mil quilômetros em quatro meses, um objetivo bastante ousado para a época devido à situação política nos países latino-americanos, além da situação dos meios e das vias de transporte e pela carência de troca de informações entre os países.

5 Referência aqui ao ensaio "El Quijote, uma lectura fronteriza”, de Juan Villoro. In: Estúdios Públicos, n. 100, p. 71-88, 2005, que vê na obra de Cervantes uma road novel. 
A rota prevista por Granado e Guevara inicia em Buenos Aires, partindo rumo ao sul, onde "Alberto vê o Atlântico pela primeira vez na vida". ${ }^{6}$ Depois disso, a parada romântica em Miramar foi mais longa que o previsto, pois foi difícil Guevara desprender-se dos laços com Chichina, sua namorada. A seguir se dirigem mais para o sul, até a Patagônia, cruzando a Cordilheira dos Andes para chegar ao sul do Chile, atravessando o país até entrar no Peru, para depois conhecerem Cuzco e Machu Picchu - "o centro do mundo" -, e finalmente trabalhar no leprosário de San Pablo, na Amazônia peruana. A viagem tem como destino final a península de Guajira, na Venezuela. Uma vez reconstituída a jornada, o filme explora extensivamente o território da Argentina, do Chile e do Peru: viajando pela Patagônia, cruzando os Andes e o deserto de Atacama, entrando na Bacia Amazônica, chegando finalmente à colônia de leprosos de San Pablo, perto de Iquitos, no Peru.

O filme obviamente não consegue e nem pretendia reproduzir fidedignamente todos os aspectos do relato de viagem de Ernesto Guevara. O diretor mantém-se, contudo, bastante fiel às palavras do diário de Guevara, havendo, porém, mudanças que em certos momentos tornam a narrativa mais romântica e por vezes até engraçada, quixotesca. Depois de lido o livro, sente-se falta no filme de situações mais claras e reais de dificuldade, como quando os dois passam fome por não terem dinheiro ou quando não conseguem dormir por causa do frio intenso, além da fome. Essas situações relatadas no livro parecem mais reais. O leitor pode visualizar uma verdadeira dificuldade nas palavras de Guevara e sente-se que a viagem realmente está se tornando difícil, talvez impossível de ser continuada. No filme, por sua vez, estes momentos de grande superação são cercados pelas características da aventura. A falta de dinheiro, a procura de lugar para pouso e as formas de conseguir alimentação são descrições constantes no livro de Ernesto Guevara - menos em tom de aventura, mas sim na tentativa de registrar esses momentos de dificuldade.

Muitas vezes, os dois conseguiram alojamento somente em postos policiais, mas isto não é narrado no filme Diários de Motocicleta. Este é outro aspecto do livro que poderia ter sido mais aprofundado no filme, na tentativa de tornar a viagem dos dois descobridores mais dura e difícil, como realmente foi a viagem desde o princípio.

A realidade de vida difícil, comum a muitos habitantes, se não à grande parte dos habitantes latino-americanos naquela época e hoje ainda, certamente influenciou Ernesto Guevara a refletir sobre a real situação de vida dessas pessoas e isso provavelmente levou -o a optar por uma vida revolucionária. Contudo, a opção do diretor certamente pretende destacar um ponto de vista da aventura dos viajantes sempre a caminho, que superam as dificuldades que encontram pela frente. O filme não se demora em pormenorizações, o que caracteriza essa narrativa de gênero Road Movie.

Nesse momento, poder-se-ia perguntar se o gênero não impede que se dê uma caracterização mais perfeita dessa viagem de formação do revolucionário Che Guevara, pois sentese falta de um destaque mais fechado da expressão das figuras centrais da narrativa, assim como da de outras que mereceram destaque no filme, como por exemplo, entre outros, os mineiros, o pequeno guia que os acompanha em Lima, a mãe do bombeiro que sofre presa à cama. Ou caberia a Salles e sua companhia destacar mais esse aspecto, sendo uma opção

${ }^{6}$ GUEVARA, Ernesto. 2003, p. 16. 
manter a câmera sempre mais aberta com o intuito de registrar não somente elementos isolados, mas esses elementos envolvidos no meio?

O filme Diários de Motocicleta reproduz a história de uma viagem iniciática no coração da identidade latino-americana, baseada no diário de Ernesto Guevara e também nos diários e relatos de Alberto Granado. Segundo Salles, a pesquisa para a realização do filme levou mais de dois anos. Depois da leitura de todas as biografias sobre Ernesto Guevara para Walter Salles, a mais completa foi a escrita pelo mexicano Paco Ignazio Taibo - foram necessárias muitas horas de entrevistas com as pessoas ligadas às duas personagens principais da história. A preparação incluiu diversas viagens a Cuba para entrevistas com Alberto Granado, um senhor que hoje conta com seus 90 anos, além de viagens à Argentina, para entrevistas com a família de Ernesto Guevara. "O apoio da viúva Aleida e dos filhos foi muito importante para que pudéssemos prosseguir", diz Walter Salles em entrevista.

O que começa como uma aventura muda pouco a pouco de forma. É importante ressaltar que inicialmente os dois jovens estudantes pretendiam unicamente realizar uma aventura pela América de fala hispânica. O confronto com a realidade social e política da América Latina, contudo, passa a alterar a percepção que os dois viajantes têm do mundo. $\mathrm{Na}$ primeira grande viagem de suas vidas, eles se deparam com as raízes profundas de um continente que é seu, mas que lhes é também estranho. A experiência vivida em um ano formativo de suas vidas vai resultar no despertar de novas vocações, associadas ao desejo de justiça social, que levarão a movimentos revolucionários, principalmente na vida de Guevara, como é de conhecimento geral hoje. Os dois jovens que inicialmente partem para uma viagem de descoberta do seu continente, encontram no novo mundo o seu lugar, seu campo de trabalho e seu campo de batalha. Nessa viagem de descoberta aprenderam in loco sobre a América Latina o que na década de 50 não se aprendia na universidade, quando esta dirigia seu olhar somente para a Europa e para os USA.

Por outro lado, o filme também tematiza a importância da relação de amizade que se consolida quando duas pessoas, neste caso, batalham por um interesse comum. Situações de dificuldade podem levar facilmente tais relações a uma ruptura. O filme caracteriza muitas dessas situações, mas Granado e Guevara mantêm-se fiéis na sua jornada. As relações de amizade e de confiança são de grande importância para que se possam abrir frentes de batalha, lutas por causas, como a dos dois viajantes argentinos que querem chegar ao leprosário de San Pablo, no Peru. As relações pessoais aparecem caracterizadas não somente no tratamento entre os dois viajantes, mas também nos diversos contatos que ambos tiveram com nativos do local, principalmente no Chile, no Peru e na Bolívia. Nestas ocasiões há situações de desconfiança, de desprezo, de recusa, mas também existe a recepção calorosa, aberta, receptiva em todos os lugares por onde passam.

Percebe-se a importante participação do roteirista José Rivera na forma como se processa essa mudança nas personagens - de jovens aventureiros a profundos conhecedores e interessados no sistema social latino-americano -, pois sua visão do que se poderia chamar de contexto social larino-americano fez com que o filme conseguisse transmitir ao espectador essa leitura. Seu objetivo foi de mostrar a humanização de duas personagens tão singulares, que se transformam, como acontece, por exemplo, no Bildungsroman (romance de formação) alemão do século XIX. Poder-se-ia chamar o filme de uma "viagem de formação" 
de Granado e Guevara. O filme relata oito meses da vida desses dois jovens - oito meses cruciais durante os quais eles se confrontaram com uma realidade que desconheciam, uma realidade que lhes pedia para fazerem escolhas na vida e finalmente decidirem que trajetória viriam a seguir.

Diários de Motocicleta é antes de mais nada um filme sobre Ernesto Guevara antes de tornar-se o "Che“ revolucionário, conforme seu filho Camilo. O filme passa o período de preparação desse Che que o mundo passaria a conhecer, principalmente depois de travar contato com os companheiros cubanos Raúl e Fidel Castro e depois da Revolução Cubana. Segundo Walter Salles, para Granado e Guevara a viagem foi decisiva para ambos pelo que ela ajudou na preparação do futuro deles. É importante ter em mente que esta é a primeira vez em que eles se aventuram pela América Latina. Eles se confrontaram com os resquícios da cultura inca e foram expostos a obras teóricas de pensadores latino-americanos tais como Mariategui. Tais experiências, tão extraordinárias e variadas, certamente os ajudaram a repensar a visão de mundo que eles tinham. Por isso também a importância do contato com nativos no filme, uma vez que a intenção de Salles e Rivera era transmitir a relevância justamente dessa relação para a formação e o interesse pelas questões sócio-políticas do povo latino-americano.

A partir desse ponto de vista, pode-se afirmar que o filme se encaixa no gênero Road Movie, visto que se processa uma transformação desses jovens aventureiros em dois atentos observadores da realidade social e política da América Latina. Para ambos, que antes conheciam principalmente autores importados dos USA e da Europa, apresentam-se durante a viagem importantes autores do contexto latino-americano que os influenciarão profundamente.

Contudo, ao espectador que consegue abstrair o que sabe sobre a vida de Che Guevara, o filme não deixa transparecer explicitamente que depois dessa viagem o mesmo viria a se tornar um revolucionário armado. Ele poderia, por exemplo, ter regressado a Buenos Aires e ter concluído seu curso de medicina, ter assumido um trabalho como médico e ter continuado uma vida profissional como uma simples pessoa de visão mais ampla depois de sua importante viagem. Neste sentido, a filme realmente apresenta um Guevara anterior ao Che que se conhece na história da América Latina, mas a trasformação para um Che de características mais revolucionárias poderia ser mais perceptível, clara e talvez corajosa, apesar de se ter consciência do peso da figura Che.

No filme, esse Ernesto Guevera mais politizado transforma-se na medida em que a viagem prossegue. No início tem-se um Ernesto apaixonado que passa mais dias que previsto na residência dos pais da namorada de classe média alta, como se viu acima. Essa relação, contudo é interrompida durante a viagem. Os 15 dólares, que Chichina lhe dá foram inicialmente guardados para lhe comprar algo nos USA, são depois dados a pobres trabalhadores das minas no Chile. Em outro momento, revoltado com o tratamento dado aos trabalhadores das minas, Ernesto Guevara joga uma pedra no caminhão que transporta os mesmos. No Peru, no dia do seu aniversário, faz um discurso que exalta o Peru e uma América Unida. É esse Ernesto Guevara, que transforma sua visão política e social durante a viagem por alguns países da América do Sul, que se tornará o conhecido Che Guevara. No filme, contudo, a sua apresentação dá-se de forma branda, tanto que, como se mencionou 
acima, Ernesto poderia ter regressado à Argentina e nunca ter se tornado um revolucionário armado. Trata-se aí, certamente, de uma opção da direção do filme.

O filme se caracteriza por não ser um documentário, mas existe o contato improvisado com nativos, usual nesta forma de filmagem. Por exemplo, no Peru, quando conversam com as índias incas. Somente através do contato com o povo latino-americano é que se consegue compreender e formar o complexo que o compõe, objetivo de Walter Salles neste filme. Também não é uma biografia de Ernesto Guevara, mas a história desta importante figura inserida e descobrindo o que se lhe tornou tão caro: a valorização da América Latino e do seu povo.

Sente-se falta, contudo, de uma aproximação maior das pesonagens com os problemas sociais das pessoas que encontram ao longo da viagem. Apesar da fotografia maravilhosa, sente-se falta de tomadas mais próximas das personagens em questão na tentativa de mostrar o real sofrimento ou então a real expressão de angústia. Para tal, cite-se novamente o exemplo dos mineiros sentados sobre as pedras, na expectativa de serem escolhidos para o trabalho. A tomada é do grupo e não se destaca a expressão de derrota, de medo, de angústia da mulher que fica para trás com outros não escolhidos. A câmara dá ao espectador uma tomada geral e não há enfoque especial na expressão das pessoas. A propósito, esse aspecto - a tomada com câmera fechada - não ocorre ou só raramente no filme. Visto que se trata de um filme que busca justamente trabalhar aspectos sociais da América Latina, o espectador sente falta desse elemento mais real do contexto latino-americano, a expressão rude e sofrida de modo mais claro.

Procurou-se trabalhar o contato com elementos nativos do local no filme. Trata-se de um aspecto importante para Salles, e no filme Diários de Motocicleta se incentivou o improviso no contato com as pessoas locais. E como resultado tem-se a participação de muitas pessoas que inicialmente não estavam previstas no filme. O próprio diretor exemplifica isso num comentário interessante sobre o assunto:

... o road movie deve ser transformado pelos encontros que ocorrerão inevitavelmente às margens da estrada. A improvisação se torna, assim, não só natural como também necessária. Nas filmagens de "Diários de Motocicleta", tentamos constantemente incorporar o que a realidade nos trazia, mesclando os atores com as pessoas que encontrávamos em cada uma das localidades que atravessávamos. Os momentos mais prazerosos que guardo da filmagem são justamente os que não foram antecipados. ${ }^{7}$

A fotografia do filme é impressionante pela sua beleza. O fotógrafo Eric Gautier mostra através de seu trabalho também aí as diversas formas que compõem o continente latino -americano. O filme não é de estúdio, sendo todas as filmagens com a câmera na mão e nele o espectador parte junto com os dois viajantes de Buenos Aires para um contexto de campo, desde a planície até os Andes. Granado e Guevara conhecem a Argentina rural, o Atlântico argentino, o pé dos Andes, os frios lagos e vales andinos, a neve dos Andes, o deserto do sul

\footnotetext{
7 Ver: http://ultimosegundo.ig.com.br/cultura/2007/11/20/sobre_a_estrutura_e_os_personagens_dos_filmes_de_estrada_1087608.html.
} 
da América do Sul, o costa do Pacífico e seus centros urbanos, a vida nua e crua das minas, os penhascos peruanos, as cidades incas, o calor úmido da região amazônica. Tudo isso em belas imagens, que, apesar de muitas vezes representarem a vida sofrida e simples desse povo que compõe o elemento latino-americano, mostram a beleza natural e humana das pessoas que vivem nesses contextos. Não se trata aqui de exaltar o grotesco ou o feio, mas de perceber que também nesses contextos existem belas imagens, no contexto latino-americano. Ao final o filme consegue passar ao espectador o desejo de saber mais sobre Guevara e Granado e também de realizar semelhante viagem para poder conhecer esses contextos deslumbrantes.

O Road Movie tem a pretensão de ser o tipo de filme que deixa o espectador ansioso para chegar ao destino, mas por outro lado, e ao mesmo tempo, que dá tempo para sorver a paisagem, que no caso de Diários de Motocicleta é fascinante.

Assim como a fotografia, a música é muito bem selecionada e se completa em uma harmonia com o todo do filme, fazendo com que os 38 minutos de música pareçam ainda mais breves. A trilha musical é composta pelo argentino Gustavo Santaolalla (autor também de Amores Brutos e 21 Gramas). A música é delicada e intimista e se adequa muito bem às imagens captadas pelo diretor Walter Salles e pelo fotógrafo Eric Gautier, formando assim um complexo em sintonia. A música de Santaolalla é produzida com vários instrumentos acústicos: violão, guitarra, ronrocco, charango, caja, flautas, percussão, vibros e baixo.

Por meio do violão, Santaolalla destaca sentimentos de isolamento ou de melancolia, em faixas como "Lago Frias", "Leaving Miramar", "Jardín”, "La morte de la Poderosa" e "Leyendo en el hospital". Os outros muitos instrumentos de percussão ressaltam a característica da música latina: "Apertura" e "La partida".

A guitarra elétrica junto com a percussão na faixa "La salida de Lima" marca a saída dos dois viajantes de Lima e que agora buscam seu grande objetivo, o leprosário de San Pablo, marcando a ansiedade de Granado e Guevara em chegar.

Em "Procéssion", "Amazonas" e "El cruce" - momento de tensão - Santaolalla deixa a música baixa e indefinida, usando basicamente solos de percussão. Já em momentos íntimos predominam os instrumentos de sopro que criam uma textura etérea, apoiando-se nas ricas imagens e invertendo, assim, a função da trilha sonora "Montaña", "Círculo en el rio" e "Partida del leprosario".

Um pouco da música com toque folclórico da música hispano e latino-americana aparece em "Chipi Chipi”, de Gabriel Rodriguez, e em "Que rico el mambo", de Dámasco Pérez Prado.

Especialmente sensível é a música "Al outro lado del río", composta especialmente para o filme por Jorge Drexler, responsável também pelos vocais e solos de violão. Esta música destacou e marcou o filme, de Walter Salles, e também foi a ganhadora do Oscar naquele ano. Mas a apresentação da música no Oscar gerou também desagrado por parte da equipe do filme e simpatizantes com a organização do evento pelo fato de Drexler não ter sido convidado para apresentar a sua música, a qual foi interpretada por Antonio Banderas e Carlos Santana. ${ }^{8}$

\footnotetext{
${ }^{8}$ Para ver mais sobre a música no filme, ver, entre outros, http://tudo-em-cima.blogspot.com/2005/06/msica-trilha-sonora-do-filme-dirios-de.html, de André Lux.
} 


\section{CONCLUSÃO}

Ao final, pode-se afirmar que o filme Diários de Motocicleta pode ser classificado como filme do gênero Road Movie por apresentar elementos que o caracterizam. Para retomar apenas alguns, cite-se: a real transformação interna das duas personagens centrais, em especial de Ernesto Guevara, a partir do contato com uma realidade externa, estranha para ambos; a forma de filmagem, apresentando diversas realidades do contexto latino-americano, destacando-se principalmente a fotografia no filme, o perfeito entrelaçamento da música, com a fotografia e o enredo, sempre apresentando características de movimento; a inclusão de elementos novos, inicialmente não previstos no roteiro, em especial os contatos com as pessoas do local por onde passavam os viajantes.

Por outro lado, o filme, que apresenta como objetivo oferecer uma leitura do contexto social da América Latina visitada pelos dois viajantes, apresenta certo distanciamento justamente dessa proposta. Como se afirmou acima, para que o espectador tivesse uma melhor percepção da realidade social do elemento latino-americano inserido no seu contexto, faltaram tomadas mais certeiras e talvez individuais das personagens. O filme dá ao espectador uma imagem desse elemento latino-americano inserido num contexto maior que é o seu meio, sendo que esse meio muitas vezes é apresentado com belas imagens que acabam por ofuscar a situação pobre e desfavorável desse elemento visto de fora.

\section{REFERÊNCIAS:}

CAETANO, Maria do Rosário. Entrevista com Walter Salles. In: Revista de Cinema. Ano 2, n. 24, abril de 2002, p. 13-20.

CAVALHEIRO, Rodrigo; BRUST, Gabriel. “Che Guevara 40 anos depois. Mocinho ou bandido.” In: Zero Hora - Mundo, Domingo, 7 de outubro de 2007, p. 34-35.

GUEVARA, Ernesto Che. De moto pela América do Sul. Diário de viagem. Trad. Diego Ambrosini. 2. ed. São Paulo: Sá, 2003.

LERINA, Roger. “A redescoberta da América.” Entrevista: Walter Salles, cineasta. In: Zero Hora Cultura, Sábado, 10 de janeiro de 2004, p. 4.

LERINA, Roger. “Sem perder a ternura jamais.” In: Zero Hora - Cultura, Sábado, 10 de janeiro de 2004, p. 6.

MOREIRA, Carlos André. “A função do cinema é apontar um porvir”. In: Zero Hora - Cultura, Sábado, 29 de janeiro de 2005, p. 4-5.

SALLES, Walter. "Versão engajada de 'On the Road'”. In: Zero Hora - Cultura, Sábado, 10 de janeiro de 2004. 
VILLORO, Juan. “El Quijote,uma lectura fronteriza”. In: Estúdios Públicos, n. 100, 2005, p. 71-88. Ver http://www.cepchile.cl/

Diários de Motocicleta, direção: Walter Salles, produção: FilmFour/ South Fork Pictures/ Tu Vas Voir Productions 2004.

Wanderlust. On the road with american road Movies, direção: Shari Springer; Berman Robert Pulcini, produção: Tailslate/IFC/Netflix 2006.

http://ultimosegundo.ig.com.br/cultura/2007/11/20/entre_a_ficcao_e_o_documentario_1087609.html. http://ultimosegundo.ig.com.br/cultura/2007/11/20/sobre_a_estrutura_e_os_personagens_dos_ filmes_de_estrada_1087608.html

http://www.dfe.uem.br/cinuem/index.php?option=com_content\&task=view\&id=46\&Itemid=40, $\mathrm{de}$ Zuleika de Paula Bueno.

http://cinemaafinseumadosedewhiskey.blogspot.com/2007/10/os-10-melhores-road-movies-do-cinema. html

http://tudo-em-cima.blogspot.com/2005/06/msica-trilha-sonora-do-filme-dirios-de.html, de André Lux. 